\title{
New type of xiphidiocercariae (Digenea: Microphalloidea) from South Vietnam
}

\author{
Darya Krupenko ${ }^{1}$, Anna Gonchar ${ }^{1,2}$, Georgii Kremnev ${ }^{1}$, Boris Efeykin ${ }^{3,4,5}$ and Vladimir Krapivin ${ }^{1,3,4}$ \\ ${ }^{1}$ Saint Petersburg University, Department of Invertebrate Zoology, Saint Petersburg, Russia; \\ ${ }^{2}$ Zoological Institute, Laboratory of Parasitic Worms and Protists, Russian Academy of Sciences, Saint Petersburg, Russia; \\ ${ }^{3}$ Severtsov Institute of Ecology and Evolution, Russian Academy of Sciences, Moscow, Russia; \\ ${ }^{4}$ The Russian-Vietnamese Tropical Scientific and Technological Centre, Southern Branch, Ho Chi Minh, Vietnam; \\ ${ }^{5}$ Kharkevich Institute for Information Transmission Problems, Russian Academy of Sciences, Moscow, Russia
}

\begin{abstract}
We found unusual digenean intramolluscan stages, sporocysts and cercariae, in gastropods Sulcospira dautzenbergiana (Morelet) (Caenogastropoda: Pachychilidae) from Southern Vietnam and named them Cercaria cattieni 1. These cercariae have a stylet and thus belong to the Xiphidiata. However, such combination of characters as extremely large body size and I-shaped excretory bladder has not been found before in any other xiphidiocercariae. We obtained COI, ITS1, 5.8S + ITS2, and 28S rDNA sequences for $C$. cattieni 1 . The latter allowed us to specify the phylogenetic position of the discovered cercariae: $C$. cattieni 1 falls within the superfamily Microphalloidea and is most closely grouped to Pachypsolus irroratus (Rudolphi, 1819) (Pachypsolidae), the sea turtle parasite. Information on the family Pachypsolidae is limited. Judging from the molecular phylogeny, C. cattieni 1 might be the larva of the Pachypsolidae, documented for the first time.
\end{abstract}

Keywords: Digenea, xiphidiocercariae, sporocysts, Xiphidiata, Microphalloidea, Pachypsolidae, 28S rDNA, ITS1, ITS2, COI

The contemporary diversity of the Digenea comprises around 18,000 species (Bray 2008), but most of these are known only from sexual adults (maritae). Some data on the life cycle are available for 5-10\% of the species (Cribb et al. 2003). Stages in the intermediate hosts are greatly understudied, and for many taxa (even at the family level) the first intermediate host remains unknown, as well as structure of cercariae and parthenogenetic generations. Since early 1990's molecular data have been a powerful tool to recognise species and link life cycle stages of digeneans, and together with morphological descriptions these methods are very helpful to elucidate digenean diversity (Blasco-Costa and Poulin 2017).

During examination of the fauna of digenean larvae in freshwater gastropods in the Cát Tiên National Park, Southern Vietnam, daughter sporocysts containing unusual xiphidiocercariae were found in the pachychilid gastropod Sulcospira dautzenbergiana (Morelet) (Caenogastropoda). Here we provide a morphological description of these life cycle stages, the sequences of COI, ITS1, 5.8S+ITS2 and $28 \mathrm{~S}$ rRNA (LSU) (domains D1-D3), and the results of the phylogenetic analysis based on the latter.

\section{MATERIALS AND METHODS}

Gastropods Sulcospira dautzenbergiana were collected on 4-5 October 2018 in a stream in Cát Tiên National Park, Southern Vietnam (11.4305N, 107.4294E). Snails were dissected to detect digenean infection. Sporocysts and cercariae found were rinsed in freshwater, fixed in $70 \%$ ethanol and later transferred to $96 \%$ ethanol for further morphological and molecular analyses. Video of living cercaria was made with a dissecting microscope and a camera Canon A720.

For morphological description sporocysts and cercariae were stained either with Ehrlich's haematoxylin or Heidenhain's iron haematoxylin. Picric acid was used to destain worms after Heidenhain's haematoxylin, and $70 \%$ ethanol with $0.1 \mathrm{M} \mathrm{HCl}$ after Ehrlich's haematoxylin. Toluidine blue was used to identify mucoid substances that give metachromatic staining. After staining, samples were dehydrated in graded alcohols and mounted in BioMount medium (Bio Optic, Milan, Italy).

Photographs of the whole-mounted cercariae and sporocysts were made using a compound microscope Leica DM 2500 (Leica Microsystem, Wetzlar, Germany) and a camera Nikon DS Fi1 in bright field and with differential interference contrast microscopy (DIC). Measurements were made in Fiji software (Schindelin et al. 2012). All measurements are in micrometres the range of values is followed by mean in parentheses.

Address for correspondence: Darya Krupenko, Saint Petersburg University, Universitetskaya nab. 7-9, Saint Petersburg, Russia. E-mail: krupenko.d@gmail.com; d.krupenko@spbu.ru 
Table 1. DNA sequences obtained for Cercaria cattieni 1.

\begin{tabular}{lllll}
\hline \multirow{2}{*}{ Fragment } & \multirow{2}{*}{ GenBank no. } & \multirow{2}{*}{ Fragment length, bp } & \multicolumn{2}{c}{ PCR and sequencing primers } \\
& & & Name (fw/rev) & References \\
\hline 28S rDNA & MN962960 & 1223 & digl2/1500R & $\begin{array}{l}\text { Tkach et al. 1999 } \\
\text { Olson et al. 2003 }\end{array}$ \\
ITS1 & MT657959 & 864 & BD1/4S & Luton et al. 1992 \\
cox rDNA+ITS2 & MT648945 & 451 & 3 S/ITS2.2 & Morgan and Blair 1995 \\
\hline
\end{tabular}

A

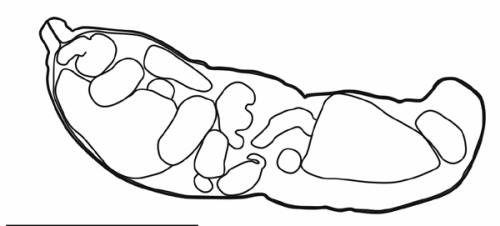

$500 \mu \mathrm{m}$

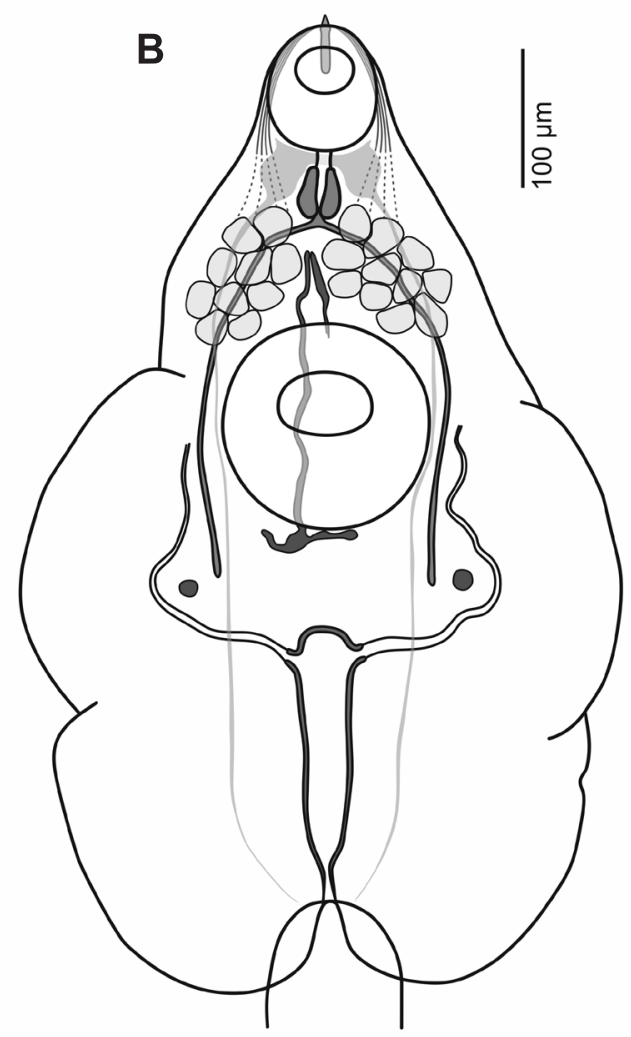

C

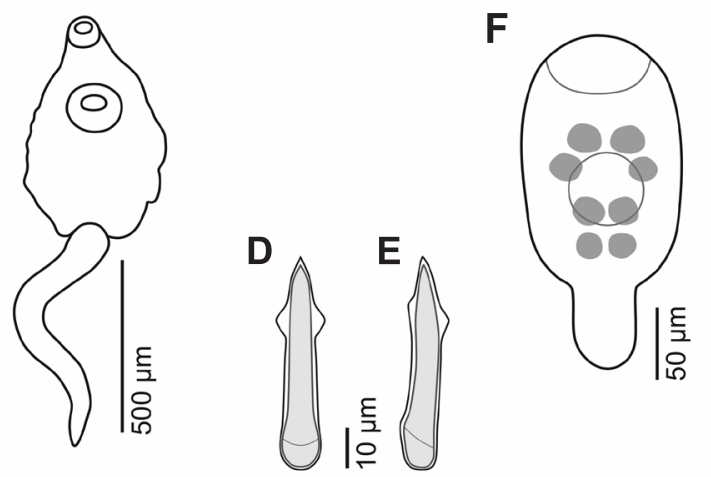

Fig. 1. Cercaria cattieni 1. A - sporocyst; B-F - cercariae; $\mathbf{B}$ - body structure; $\mathbf{C}$ - general view; $\mathbf{D}, \mathbf{E}$ - stylet, ventral (D) and lateral (E) view; F - scheme of cercarial embryo with mucoid glands (grey).
For molecular analysis two sporocysts were removed from $96 \%$ ethanol and dried; DNA was extracted from each of them separately by incubation in $200 \mu \mathrm{l} 5 \%$ Chelex ${ }^{\circledR} 100$ resin (BioRad, Hercules, California, USA) solution with $0.2 \mathrm{mg} / \mathrm{ml}$ proteinase $\mathrm{K}$ at $56^{\circ} \mathrm{C}$ overnight; $8 \mathrm{~min}$ at $90^{\circ} \mathrm{C}$; and centrifugation at $16,000 \mathrm{~g}$ for $10 \mathrm{~min}$. Supernatant containing DNA was then transferred to a new tube and stored at $-20^{\circ} \mathrm{C}$. Amplifications were performed in $25 \mu \mathrm{l}$ reaction mixtures containing $17 \mu \mathrm{l}$ Super-Q ${ }^{\circledR}$ water, $5 \mu$ ScreenMix-HS reaction mix (Evrogen, Moscow, Russia), $0.5 \mu \mathrm{l}$ of each forward and reverse primer $(10 \mathrm{pmol} / \mu \mathrm{l})$, and $2 \mu \mathrm{l}$ of the DNA template. PCR products were stained with SYBR ${ }^{\circledR}$ Green (Invitrogen, Carlsbad, California, USA), size-separated by electrophoresis in a $1 \%$ agarose gel, and visualised using ChemiDoc MP (BioRad, USA). Primers that we used to amplify and sequence the 28S rDNA, ITS1, $5.8 \mathrm{~S}+\mathrm{ITS} 2$ and COI are listed in Table 1. Sequencing was performed on ABI PRISM 3500xl (Applied Biosystems, Foster City, California, USA).

Data were analysed using Geneious ${ }^{\circledR} 11.1 .5$ (https://www. geneious.com). BLAST was used for preliminary assessment of new sequences. Relevant 28S rDNA sequences from GenBank were used in alignments and phylogenetic reconstructions. The best substitution model was determined as $\mathrm{GTR}+\mathrm{I}+\mathrm{G}$ with $\mathrm{BIC}$ in jModelTest 2.1.10 (Darriba et al. 2012). MrBayes v.3.2.6 (Ronquist et al. 2012) was used to build a tree via the Bayesian inference method. Brachycladium goliath (van Beneden, 1858) (family Brachycladiidae) (KR703279) served as an outgroup. To estimate genetic distances, we used a Maximum Composite Likelihood model in MEGA 7 (Kumar et al. 2016); standard errors were obtained by a bootstrap procedure (1,000 replicates).

\section{RESULTS}

Of $41 S$. dautzenbergiana dissected, one snail was infected with daughter sporocysts containing unidentified xiphidiocercariae - Cercaria cattieni 1 .

Superfamily Microphalloidea Ward, 1901

Cercaria cattieni 1

Fig. 1

First intermediate host: Sulcospira dautzenbergiana (Morelet, 1884) (Caenogastropoda: Pachychilidae).

L o c a lity: Stream in Cát Tiên National Park, Southern Vietnam $(11.4305 \mathrm{~N}, 107.4294 \mathrm{E})$.

Prevalence: $2 \%(n=41)$.

Site of infection: Digestive gland.

Voucher specimens: Five slides from one gastropod specimen were placed in the collection of the Department of Invertebrate Zoology of Saint Petersburg University under numbers V2018F01-1-V2018F01-5

Daughter sporocysts (measurements based on six fixed specimens; Figs. 1A, 2A): 

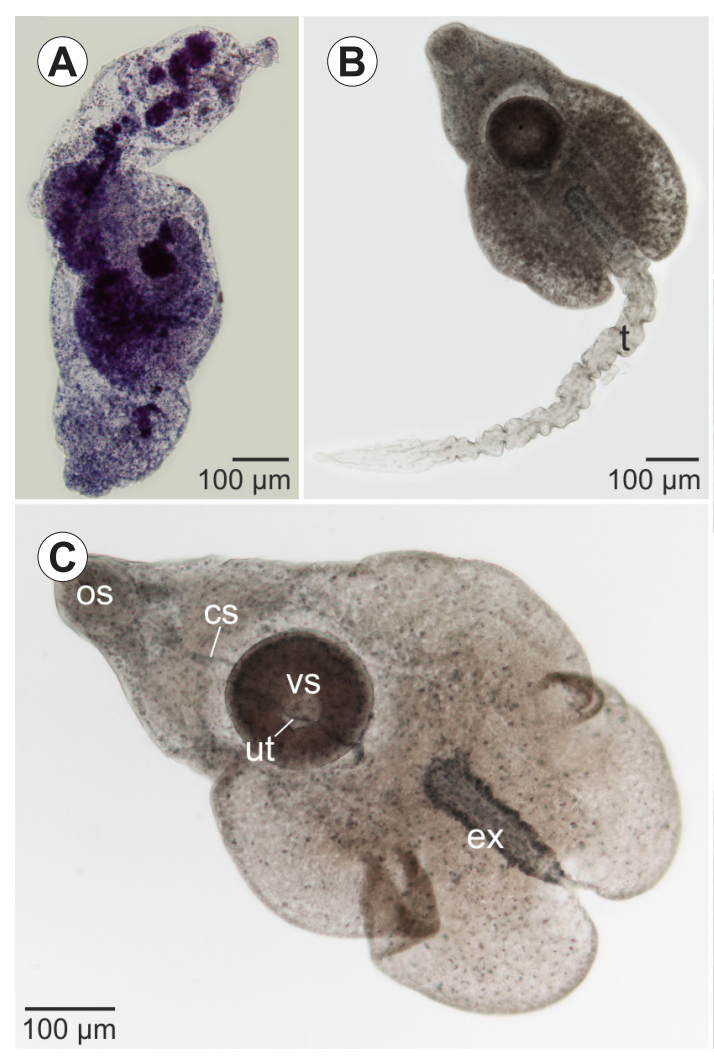
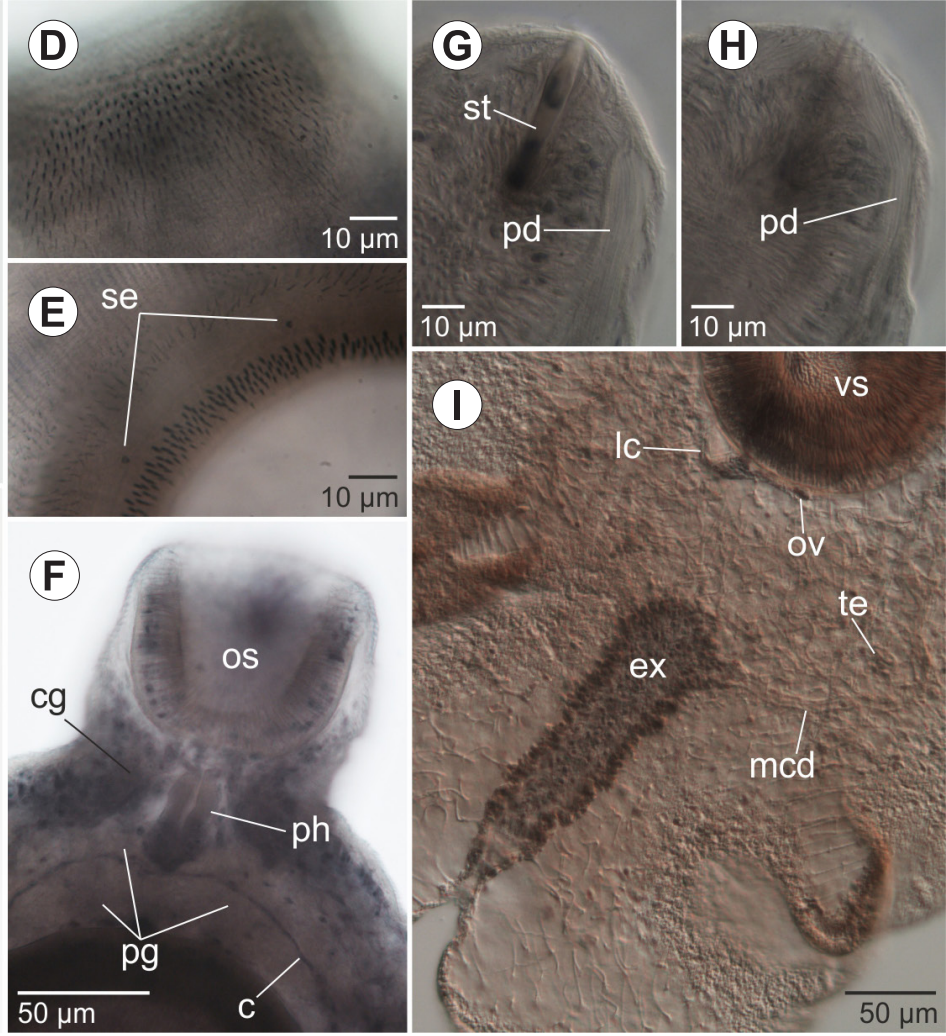

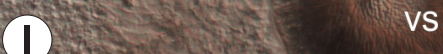

S

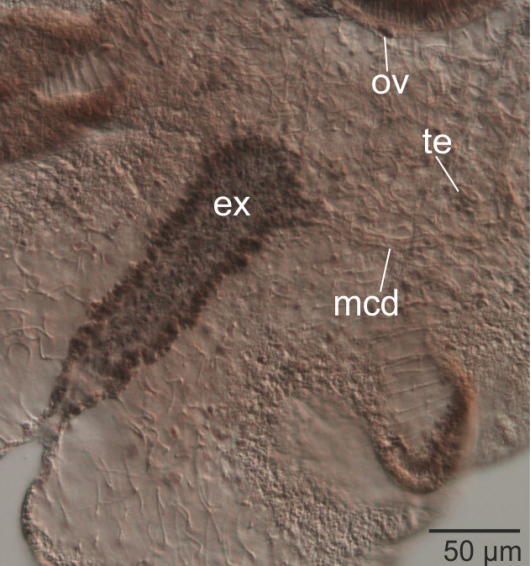

Fig. 2. Microphotographs of Cercaria cattieni 1 stained with Erlich's haematoxylin (A) and Heidenhain's iron haematoxylin (B-I). $\mathbf{A}$ - daughter sporocyst; B - underdeveloped cercaria; C - cercaria at late stage of development (tail lost during fixation); oral (os) and ventral (vs) sucker, excretory bladder (ex), primordia of cirrus sac (cs) and uterus (ut) are visible; D, E - spination of the oral sucker (D) and ventral sucker (E) rim (DIC); note sensory papillae (se) on $\mathbf{E} ; \mathbf{F}$ - forebody of cercaria (DIC), caeca (c), cephalic ganglia (cg), oral sucker (os), penetration glands (pg) and pharynx (ph) are visible; $\mathbf{G}, \mathbf{H}$ - ducts of penetration glands going along the oral sucker, opening near the stylet (st) tip (DIC); I - hindbody of the cercaria (DIC); primordia of ovary (ov) and Laurer's channel (lc) are visible posterior to the ventral sucker (vs); main collecting duct (mcd) starts anterolaterally from the excretory bladder (ex) and goes around testis primordium (te).

Sporocysts white, elongate, 799-1,628 × 291-369 (1,124 × 336), contain cercariae at different stages of development.

Cercariae (measurements based on 21 fixed specimens; Figs. 1 B-E, 2 B-I): Body 481-758 (594) long, 285-460 (369) wide, pear-shaped, narrow at fore end. Hindbody wide, with folded margins. Tegument with simple spines, most densely arranged in forebody; largest spines in midbody. Tail simple, 603-841 (697) long, 69-101 (93) wide at base, with smooth tegument. Oral sucker subterminal, spherical, 69-103 × 66-102 $(86 \times 85)$. Its rim armed with simple spines thicker than body spines, their size reduces posteriorly (Fig. 2D). Stylet 43-52 (48) long, 5-8 (7) wide at base, single-pointed, with anterior thickening (Figs. 1D,E, $2 \mathrm{G})$. Ventral sucker spherical, 142-196 × 140-204 $(160 \times$ 165); 4-5 irregular rows of spines (thicker than body spines) lie at sucker rim, around opening, surrounded by smooth zone with 6 large papillae (probably, sensory receptors) (Fig. 2E).

Prepharynx short; pharynx 28-47 × 20-41 $(37 \times 28)$; oesophagus very short. Caecal primordia composed of single row of cells (Fig. 2F), 3-6 (4) wide, extending nearly to level of excretory vesicle. Paired cephalic ganglia conspicuous, posterior to oral sucker, interconnected by dorsal commissure between pharynx and oral sucker. Dorsal and ventral pairs of longitudinal nerve chords visible along whole body. Penetration glands numerous, in forebody, anterolateral to ventral sucker (Fig. 2F). Ducts of penetration glands proceed along dorsal surface of oral sucker and open as two groups, lateral to stylet pouch (Fig. 2G,H).

Excretory vesicle I-shaped, 164-232 × 34-67 $(189 \times$ 47). Main collecting ducts starting from excretory vesicle anterolaterally (Fig. 2I). Flame-cell formula not determined. Primordia of testes symmetrical, 12-15 (13) in diameter, anterolateral to excretory vesicle. Cirrus sac primordium anterior to ventral sucker. Primordia of uterus, Laurer's channel and ovary also visible (Fig. 2I). Cercariae swim with their body contracted, thus taking saucer-shape; elongated tail beats vigorously (Supplementary material).

Mucoid glands found in cercarial embryos as four pairs of cells, anterior, lateral and posterior to ventral sucker (Fig. 1F, 3A). Later these cells form numerous dendrites remaining close to ventral surface (Fig. 3B, C). At a certain stage, part of mucoid transferred into region of stylet pouch (Fig. 3D). Next, metachromatic staining disappears from stylet pouch, being found on cercarial surface (Fig. 3E). Mucoid from rest of glands transferred into body tegument, mostly in middle third of body (Fig. 3F-H).

We obtained sequences of three fragments of the rDNA and the mitochondrial COI gene for C. cattieni 1 (Table 1). None of these sequences had any close BLAST hits. Preliminary 28S rDNA-based phylogenetic analysis (covering 

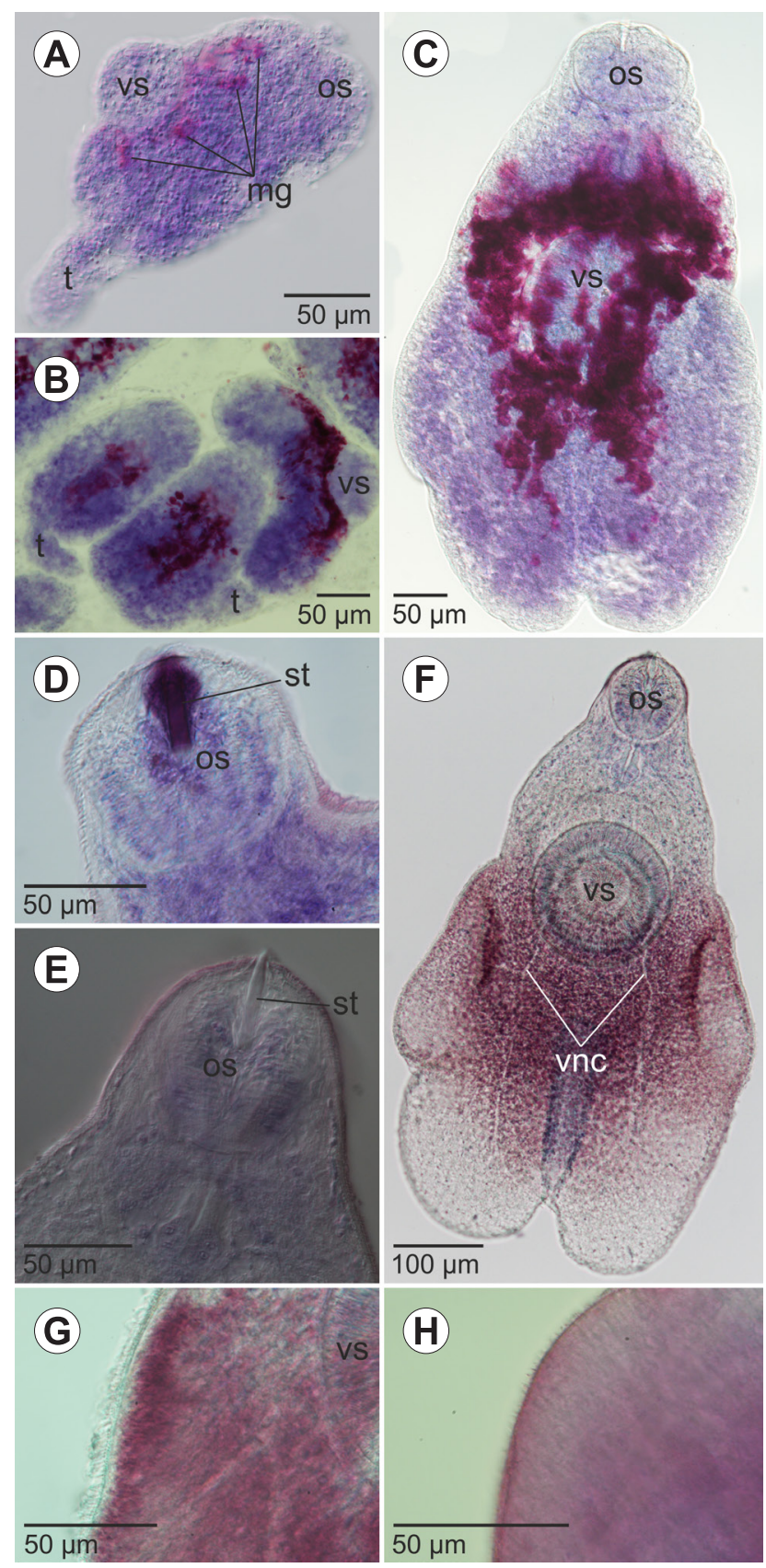

Fig. 3. Toluidine blue staining of Cercaria cattieni 1 . A - cercarial embryo, lateral view, early stage of mucoid glands ( $\mathrm{mg}$ ) formation; B - cercarial embryos at different stage, metachromatic staining shows mucoid glands; C - later cercarial embryo (tail lost during fixation), metachromatic staining of mucoid glands with numerous dendrites; D - mucoid staining of stylet pouch; $\mathbf{E}$ - mucoid on the surface of the fore region; $\mathbf{F}, \mathbf{G}$ - mucoid in the midbody, beneath musculature and tegument; ventral nerve chords (vnc) are visible among mucoid; $\mathbf{H}$ - midbody, mucoid transferred to the tegument. os - oral sucker; vs - ventral sucker; $\mathrm{t}$ - tail. A, D, E, G, H - differential interference contrast.

a broad range of taxa within the Xiphidiata) suggested focusing the dataset on the Microphalloidea and particularly the Renicolidae. The final alignment included 40 sequences and was 1,226 bp long, including 39 gaps. The resulting phylogenetic tree (Fig. 4) featured two major clades corresponding to the Microphalloidea and Plagiorchioidea. One of the lineages within the Microphalloidea included the families Renicolidae, Eucotylidae, the unknown family with unidentified cercariae from Nigeria (KX022508 and KX022509, Awharitoma and Enabulele 2018), and also C. cattieni 1 forming a well-supported clade with Pachypsolus irroratus (Rudolphi, 1819) (family Pachypsolidae) (AY222274).

\section{DISCUSSION}

Tropical fauna of digeneans is apparently much understudied and no wonder that some findings may be strikingly unlike anything previously described. Among digeneans found in freshwater gastropods of South-East Asia (Sewell 1922, Ito et al. 1962, Ditrich et al. 1992, Dechruksa et al. 2007, Jayawardena et al. 2011, Besprozvannykh et al. 2013, Chontananarth and Wongsawad 2013, and others) nothing similar to Cercaria cattieni 1 has been reported. Survey of the literature considering digenean larvae in other geographical regions and other types of environment (marine, terrestrial) produced the same result. According to the classification of Lühe (1909), C. cattieni 1 has to be placed into the armate type of xiphidiocercariae. However, such combination of characters as I-shaped excretory bladder, extremely large body size and advanced primordium of the reproductive system is very unusual and has not been described previously for any xiphidiocercariae.

The process of mucoid formation in C. cattieni 1 has similarities with other xiphidiocercariae. Numerous dendrites of mucoid glands were previously described in Cercaria longistyla McCoy, 1929 by Kruidenier (1953). Four pairs of mucoid glands were found in various xiphidiocercariae (Galaktionov and Malkova 1994, Shchenkov 2012, Shchenkov et al. 2019).

According to the results of the molecular genetic analysis, C. cattieni 1 certainly belongs to the Microphalloidea, and within this superfamily to the clade comprising the Pachypsolidae, Eucotylidae and Renicolidae with high nodal support. Close relationship between C. cattieni 1 and Pachypsolus irroratus gives us a clue to the systematic position of these cercariae. The family Pachypsolidae was established for the only genus Pachypsolus Looss, 1901 by Yamaguti (1958) with sexual adults inhabiting sea turtles and freshwater crocodilians (Blair 2008). No life cycles of the Pachypsolidae have been elucidated. In the digenean phylogeny inferred by Olson et al. (2003) this family is a sister group to the Renicolidae + Eucotylidae, and our data confirm this general topology.

The member of the family Pachypsolidae appears as the closest relative of $C$. cattieni 1 so far.

Some of the morphological characteristics support similarity of C. cattieni 1 cercariae and adults of Pachypsolus to a certain degree. The shared features are the tegument with spines, position of suckers, short oesophagus, position of testes, ovary and cirrus sac, and I-shaped excretory vesicle (Blair 2008; present data). However, they differ in the body shape and digestive system: species of Pachypsolus lack a prepharynx and their caeca are inflated and have anterior diverticula. These comparisons should be treated critically because allometric growth during the development from cercaria to sexual adult may substantially affect morphology. 


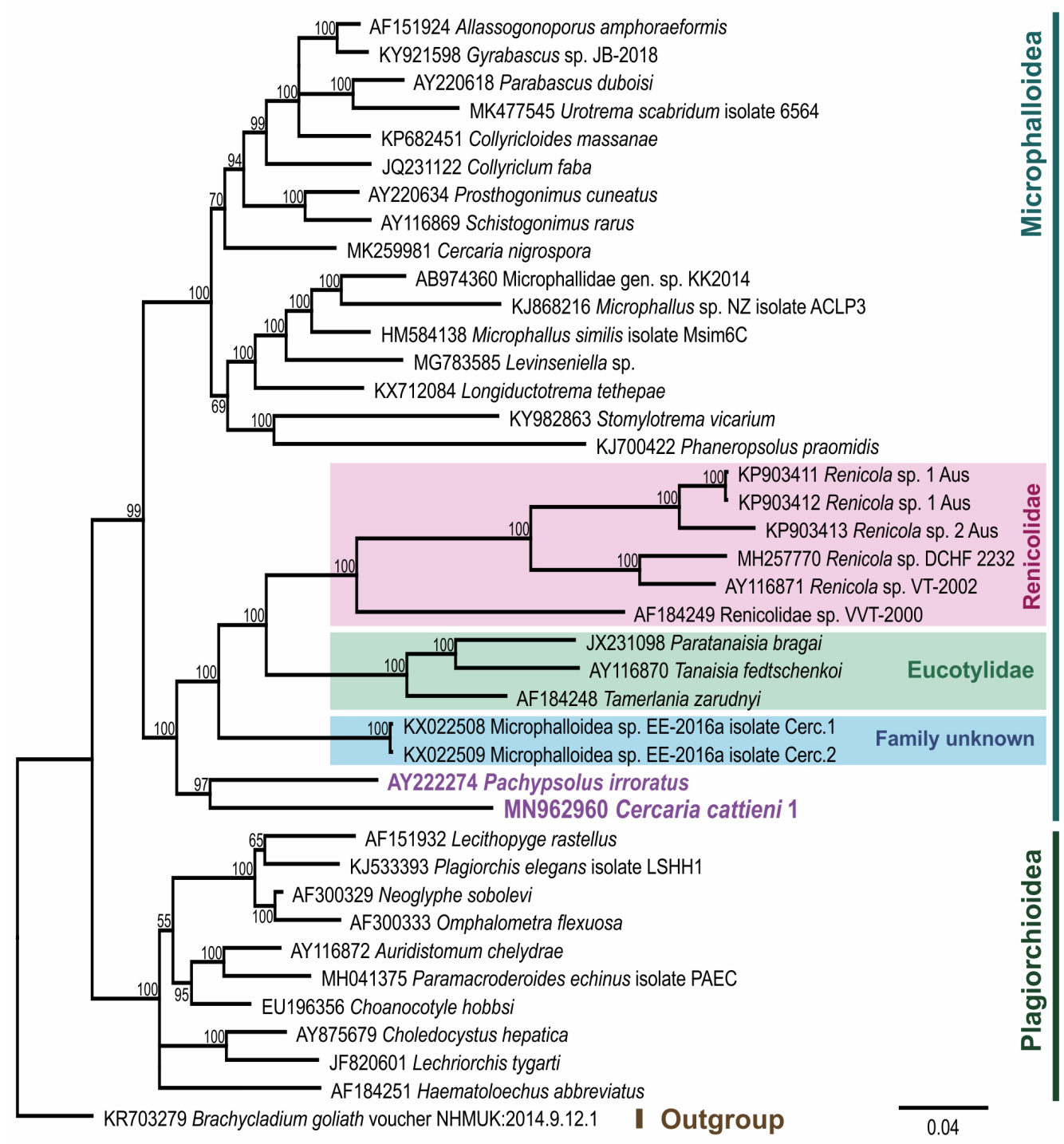

Fig. 4. Phylogenetic position of Cercaria cattieni 1 within the Microphalloidea based on 28S rDNA sequence data analysis with Bayesian inference. Posterior probabilities are printed next to nodes; scale bar shows substitution rate.

We suppose that the new type of xiphidiocercariae C. cattieni 1 is related or even belongs to the Pachypsolidae. Another option is that it forms a separate branch within the clade comprising the Pachypsolidae, Eucotylidae and Renicolidae. When sequences from more taxa are added to the tree in future, its topology, including the position of $C$. cattieni 1 , may change. Recent discovery of new lineages within the Microphalloidea that cannot be placed in any existing family (Awharitoma and Enabulele 2018, Shchenkov et al. 2020) along with our data suggest that current understanding of the diversity in this superfamily is very limited, even at the high taxonomic level. To better resolve the position of $C$. cattieni 1 , more molecular data on the Pachypsolidae are required.

Supplementary material. The video of living cercariae is available at DOI: $10.13140 /$ RG.2.2.10264.62726

Acknowledgements. The authors are grateful to Frank Koehler (Australian Museum, Sydney) for his help with host identification. A.G. was supported by the research programme of the Zoological Institute of the Russian Academy of Sciences (project number AAAA-A19-119020690109-2). We thank the research resource centre "Molecular and Cell Technologies" of Saint Petersburg State University for providing sequencing facilities.

\section{REFERENCES}

Awharitoma A.O., Enabulele E.E. 2018: Molecular phylogenetic location of a digenean larva isolated from the African ampullariid snail, Pila ovata, from Obazuwa in Edo State, Nigeria. Nigerian J. Parasitol. 39: 189-193.
Besprozvannykh V., Ngo H., Ha N., Hung N., Rozhkovan K., Ermolenko A. 2013: Descriptions of digenean parasites from three snail species, Bithynia fuchsiana (Morelet), Par- 
afossarulus striatulus Benson and Melanoides tuberculata Müller, in North Vietnam. Helminthologia 50: 190-204.

Blair D. 2008: Family Pachypsolidae Yamaguti, 1958. In: D.I Gibson, A. Jones, R.A. Bray (Eds.), Keys to the Trematoda, Vol 3. CAB International, Wallingford, and Natural History Museum, London, pp. 541-543.

Blasco-Costa I., Poulin R. 2017: Parasite life-cycle studies: a plea to resurrect an old parasitological tradition. J. Helminthol. 91: 647-656.

BRAY R.A. 2008: Introduction and key to superfamilies. In: R.A. Bray, D.I. Gibson, A. Jones (Eds.), Keys to the Trematoda, Vol 3. CAB International Wallingford and Natural History Museum, London, pp. 1-5.

Chontananarth T., Wongsawad C. 2013: Epidemiology of cercarial stage of trematodes in freshwater snails from Chiang Mai province, Thailand. Asian Pacific J. Trop. Biomed. 3: 237-243.

Cribb T.H., Bray R.A., Olson P.D., Littlewood D.T.J. 2003: Life cycle evolution in the Digenea: a new perspective from phylogeny. Adv. Parasitol. 54: 197-254.

Darriba D., Taboada G.L., Doallo R., Posada D. 2012 jModelTest 2: more models, new heuristics and parallel computing. Nat. Methods 9: 772

Dechruksa W., Krailas D., Ukong S., Inkapatanakul W., Koonchornboon T. 2007: Trematode infections of the freshwater snail family Thiaridae in the Khek River, Thailand. Southeast Asian J. Trop. Med. Publ. Hlth. 38: 10161028.

Ditrich O., Našincová V., Scholz T., Giboda M. 1992: Larval stages of medically important flukes (Trematoda) from Vientiane province, Laos. Part II. Cercariae. Ann. Parasitol. Hum. Comp. 67: 75-81.

Galaktionov K.V., Malkova I.I. 1994: The glands of trematode cercariae of the family Microphallidae Travassos, 1920. Int. J. Parasitol. 24: 595-604.

Ito J., Papasarathorn T., Tongkoom B. 1962: Studies on cercariae from fresh water snails in Thailand. Jpn. J. Med. Sci. Biol. 15: 249-270.

Jayawardena U., Rajakaruna R., Amerasinghe P. 2011: Cercariae of trematodes in freshwater snails in three climatic zones in Sri Lanka. Ceylon J. Sci. Biol. Sci. 39: 95-108.

Kruidenier F.J. 1953: Studies on the formation and function of mucoids in cercariae: non-virgulate xiphidiocercariae. Am. Midl. Nat. 50: 382-396.

Kumar S., Stecher G., Tamura K. 2016: MEGA7: Molecular Evolutionary Genetics Analysis version 7.0 for bigger datasets. Mol. Biol. Evol. 33: 1870-1874.

LÜHE M. 1909: Parasitische Plattwürmer. I. Trematoden. Süsswasserfauna Deutschlands 17: 1-217.
Luton K., Walker D., Blair D. 1992: Comparisons of ribosomal internal transcribed spacers from two congeneric species of flukes (Platyhelminthes: Trematoda: Digenea). Mol. Biochem. Parasitol. 56: 323-327.

Miura O., Kuris A.M., Torchin M.E., Hechinger R.F., Dunham E.J., Chiba, S. 2005: Molecular-genetic analyses reveal cryptic species of trematodes in the intertidal gastropod, Batillaria cumingi (Crosse). Int. J. Parasitol. 35: 793-801.

Morgan J.A.T., BLAIR D. 1995: Nuclear rDNA ITS sequence variation in the trematode genus Echinostoma: an aid to establishing relationships within the 37-collar-spine group. Parasitology 111: 609-615.

Olson P.D., Cribb T.H., Tkach V.V., Bray R.A., Littlewood D.T.J. 2003: Phylogeny and classification of the Digenea (Platyhelminthes: Trematoda). Int. J. Parasitol. 33: 733-755.

Ronquist F., Teslenko M., van derMark P., Ayres D.L., Darling A., Höhna S., Larget B., Liu L., Suchard M.A., Huelsenbeck J.P. 2012: MrBayes 3.2: efficient Bayesian phylogenetic inference and model choice across a large model space. Syst. Biol. 61: 539-542.

Schindelin J., Arganda-Carreras I., Frise E., Kaynig V., Longair M., Pietzsch T., Preibisch S., Rueden C., SaAlfeld S., Schmid B., Tinevez J.Y., White D.J., Hartenstein V., Eliceiri K., Tomancak P., Cardona A. 2012: Fiji: an open-source platform for biological-image analysis. Nat. Methods 9: 676-682.

Sewell R.S. 1922: Cercariae indicae. Ind. J. Med. Res. 10: $1-370$.

ShChenkov S.V. 2012: [Mucoid glands of Cercaria baushii 6 (xiphidiocercariae: cercariae microcotylae).] Parazitologiya 46: 314-319. (In Russian.)

Shchenkov S.V., Denisova S.A., Kremnev G.A., DobrovOLSKIJ A.A. 2020: Five new morphological types of virgulate and microcotylous xiphidiocercariae based on morphological and molecular phylogenetic analyses. J. Helminthol. 94: e94.

Shchenkov S.V., Denisova S.A., Smirnova A.D., ShunaTOVA N.N. 2019: [Mucoid glands of cercariae.] Invertebr. Zool. 16: 377-392. (In Russian.)

Tkach V., Grabda-Kazubska B., Pawlowski J., SwiderSKI Z. 1999: Molecular and morphological evidence for close phylogenetic affinities of the genera Macrodera, Leptophallus, Metaleptophallus and Paralepoderma (Digenea, Plagiorchiata). Acta Parasitol. 44: 170-179.

Yamaguti S. 1958: Systema Helminthum. Volume I. The Digenetic Trematodes of Vertebrates. Part I. Interscience Publishers, New York, 1575 pp.

Cite this article as: Krupenko D., Gonchar A., Kremnev G., Efeykin B., Krapivin V. 2020: New type of xiphidiocercariae (Digenea: Microphalloidea) from South Vietnam. Folia Parasitol. 67: 033. 